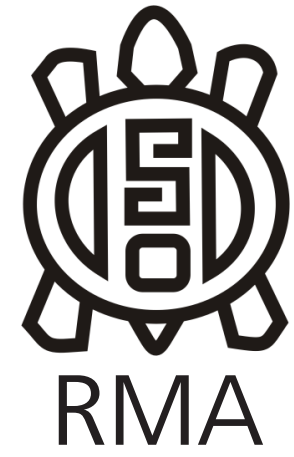

Museología

\title{
Desafiando al silencio: Reflexiones entre la museología y la antropología
}

\author{
Challenging silence: \\ Reflections between museology and anthropology
}

Veronica Jeria*, Verónica Stáffora**, Sebastián Cohen*** y Andrea Pegoraro****

*Universidad de Buenos Aires. Facultad de Filosofía y Letras. Museo Etnográfico "Juan B. Ambrosetti". Buenos Aires, Argentina. E-mail: verona28@yahoo.com

**Universidad de Buenos Aires. Facultad de Filosofía y Letras. Museo Etnográfico "Juan B. Ambrosetti". Buenos Aires, Argentina. E-mail: vstaffora@yahoo.com.ar

***Universidad de Buenos Aires. Facultad de Filosofía y Letras. Museo Etnográfico

"Juan B. Ambrosetti". Buenos Aires, Argentina. E-mail: sebafcohen@hotmail.com

****Universidad de Buenos Aires. Facultad de Filosofía y Letras. Museo Etnográfico "Juan B. Ambrosetti". Buenos Aires, Argentina. E-mail: anpegora@gmail.com

\begin{abstract}
Resumen
El Museo Etnográfico "Juan B. Ambrosetti" fue afectado por las intervenciones de las universidades nacionales de los gobiernos dictatoriales entre 1930 y 1983. Tras el retorno democrático, la Dirección de J. A. Pérez Gollán y M. Dujovne inició una transformación institucional a la luz de los debates sobre el rol de los museos de antropología. Su Proyecto difundido hace veinticuatro años en la Revista Runa influye, aún hoy, en el desarrollo de diversas líneas de trabajo. La exhibición "Desafiando al silencio: pueblos indígenas y dictadura", inaugurada a cuarenta años del último golpe de estado, es resultado de este proceso de cambios.

Como parte del equipo que la llevó adelante, nos proponemos reflexionar sobre esta exhibición a la luz de las transformaciones conceptuales y museográficas propuestas en aquel Proyecto. Y nos preguntamos icómo reflexionar sobre la violencia del estado, las resistencias, las ausencias, los silencios y las demandas de justicia en un museo universitario de antropología?
\end{abstract}

Palabras clave: Museo antropológico; Exhibiciones; Dictadura; Patrimonio cultural; Pueblos Indígenas.

\begin{abstract}
The Ethnographic Museum "Juan B. Ambrosetti" was affected by the interventions of the national universities of the dictatorial governments between 1930 and 1983. After the democratic return, the Directorate of JA Pérez Gollán and $M$. Dujovne began an institutional transformation in light of debates about the role of anthropology museums. His project spread twenty-four years ago in Runa influences, even today, the development of various lines of work. The exhibition "Challenging silence: indigenous peoples and dictatorship", inaugurated forty years after the last coup d'état, is the result of this process of change.

As part of the work team that developed it, we propose to reflect on this exhibition in light of the conceptual and museum transformations proposed in that Project. And we ask ourselves how to reflect on state violence, resistance, absences, silences and demands for justice in a university museum of anthropology?
\end{abstract}

Keywords: Anthropological Museum; Exhibitions; Dictatorship; Cultural Heritage; Indigenous Peoples.

\section{Introducción}

El Museo Etnográfico "Juan B. Ambrosetti" (ME en adelante) es un instituto de la Facultad de Filosofía y Letras. Como toda la UBA, su historia y desarrollo estuvieron atravesados por los avatares de la política nacional, y particularmente por las sistemáticas intervenciones sufridas en las universidades nacionales durante los gobiernos de facto. Con el retorno de la democracia asumió la dirección Alberto Rex González¹. Luego, en 1987, José Antonio Pérez Gollán² y Marta

\footnotetext{
1 (1918-2012). Arqueólogo, antropólogo y médico. Director del ME entre 1984-1987

2 (1937-2014). Arqueólogo y Doctor en Historia. Director del ME entre 1987-2005
} 
Dujovne ${ }^{3}$ definieron un Proyecto Institucional, cuyo balance fue publicado en la revista RUNA en 1995. La exhibición "Desafiando al silencio: pueblos indígenas y dictadura" es resultado de este proceso de cambios.

Esta muestra inaugurada en 2016, a cuarenta años del último golpe de estado, aborda la historia contemporánea incluyendo a los grupos indígenas como sujetos sociales con participación política, sindical y como parte de la clase trabajadora. Y sostiene una idea de Museo atravesado por las problemáticas actuales y la necesaria vinculación con los pueblos originarios.

En este artículo nos proponemos reflexionar sobre esta exhibición, mostrando la articulación entre sus objetivos y las transformaciones conceptuales y museográficas propuestas en el proyecto mencionado.

\section{El origen del Museo Etnográfico: sociedades exóticas, primitivos contemporáneos y diversidad cultural}

El ME fue creado en 1904 en la Facultad de Filosofía y Letras de la Universidad de Buenos Aires, como un gabinete para la investigación, enseñanza y difusión de la prehistoria y etnografía americanas. La nueva institución quedaba a cargo de Juan B. Ambrosetti (1865-1917) profesor suplente de la cátedra de Arqueología Americana de dicha Facultad, y reconocido naturalista, arqueólogo, viajero y coleccionista 4 .

Asimismo se procuró que las colecciones aunque centradas en la arqueología y etnografía americanas sirvieran para dar cuenta, de un modo más general, de todas las culturas no europeas. Para formarlas se organizaron expediciones arqueológicas y etnográficas, se encauzaron las donaciones de los particulares, se encargaron "misiones etnográficas" y viajes de estudio a diferentes regiones, se organizaron canjes con otros museos de Europa y Estados Unidos (Dujovne, Pegoraro, Pérez Gollán, 1997) y se extendió una red de recolección de objetos etnográficos de grupos indígenas de distintas regiones del país a través del aparato burocrático del Estado Nacional, convocando a personal del Ejército y agentes administrativos de los gobiernos de los Territorios Nacionales. De esta manera desde los primeros años de su funcionamiento, el Museo Etnográfico almacenaba un acervo heterogéneo en cuanto al tipo y procedencia de las piezas; por ejemplo, desde 1908 se exhibían en sus salas, piezas de África, Oceanía y Asia, ingresados a través de canjes con otros museos del mundo y de la adquisición a comerciantes especializados en objetos etnográficos (Pegoraro, 2005, 2009).

\footnotetext{
${ }^{3}$ Lic. en Letras de la UBA y especialista en temas de museos. Secretaria académica del ME entre 1987-2012

${ }^{4}$ Para realizar un recorrido cronológico por la historia institucional del museo, su devenir y principales figuras, consultar: http://museo.filo. uba.ar/fondos-documentales-institucional
}

En líneas generales, la formación de su acervo no escapa al gran período de auge de los museos de antropología en Europa y América que tuvo lugar entre la segunda mitad del siglo XIX e inicios del XX. Sus colecciones formadas bajo el modelo de la sociedad colonialista, con objetos "exóticos" de sociedades del mundo no Occidental y llamadas en aquel entonces "primitivas", confrontaban la imagen occidental, el "nosotros" con la de "otros" (Clifford, 1988; Stocking, 1985).

\section{Nuevo contexto: la descolonización y el patrimonio de los museos}

Los procesos de descolonización del siglo XX y las grandes migraciones pusieron en crisis a los museos en general y a los museos de antropología en particular (Hainard 2007, Dubuc 2002; Bustamante, 2012; Roigé, 2016). Herederos de las tradiciones coloniales y de procesos de dominación y homogeneización interna, debieron replantearse la mirada y las narraciones que transmiten sobre las otras culturas, y su función social, el lugar que ocupan como instancias de inclusión, exclusión y reproducción social (Bennet 1995, Kirshenblatt-Gimblet 1998, Hein 2000; Simpson, 2009).

En este proceso de cambios sociales y culturales, surgieron nuevas líneas teóricas para reinterpretar y redefinir el papel de los museos en la sociedad. Un rol central fue el de Hughes De Varine, arqueólogo, historiador y museólogo francés, director de ICOM $^{5}$ internacional entre 1965 y 1974, uno de los más reconocidos impulsores de lo que hoy conocemos como Nueva Museología.

Mientras se expandía la ola de descolonizaciones, desde la India en 1949 hasta los países africanos en los años 60; con la herencia de los museos coloniales y con nuevas experiencias como el Museo de Niamey; se multiplicaban los museos al aire libre y los museos rurales en Europa; urgían las luchas por los derechos civiles y se creaban los museos barriales o de vecindad en Estados Unidos; y se desarrollaba la revolución cubana, avanzaban las reivindicaciones identitarias y surgían movimientos insurgentes a lo largo y a lo ancho de Latinoamérica; De Varine sostenía:
"A partir de principios del siglo XIX, el desarrollo de los museos en el resto del mundo es un fenómeno puramente colonialista. Fueron los países europeos quienes impusieron a los no europeos sus métodos de análisis de fenómenos y patrimonios culturales; obligaron a las élites y a los pueblos de esos países a ver su propia

\footnotetext{
${ }^{5}$ International Council of Museum (ICOM) es una ONG internacional de museos y profesionales que mantiene relaciones formales con la UNESCO y tiene estatus consultivo en el Consejo Económico y Social de las Naciones Unidas.
} 
cultura como los europeos. Así, los museos en la mayoría de las naciones son creaciones de la etapa histórica colonialista.

\section{[...] La descolonización que se registró más tarde fue política, pero no cultural, puede decirse, por consiguiente, que el mundo de los museos, en tanto instituciones y en cuanto a método de conservación y de comunicación del patrimonio cultural de la humanidad es un fenómeno europeo que se difundió porque Europa produjo una cultura dominante y los museos son una de las instituciones derivadas de esa cultura." (De Varine, 1979:12)}

A partir de los años sesenta se produjeron una serie de debates, reflexiones y transformaciones en el ámbito profesional de museos, en el ICOM y especialmente en el sector latinoamericano, con un fuerte cuestionamiento hacia el rol social de los museos tradicionales y su vinculación con los pueblos indígenas, las comunidades rurales y subalternas ${ }^{6}$. En ese marco surgió un nuevo paradigma: la Nueva Museología, que venía a redefinir los ejes fundamentales de la institución museo. No debía ya considerarse un edificio sino una región, no debíamos pensar en términos de una colección sino de un patrimonio regional, y el público se transformaba en una comunidad regional participativa (De Varine, 1979). Tres conceptos le darían sustento: territorio-patrimoniocomunidad. Y la Declaración de la Mesa Redonda de Santiago de 1972, desarrollada en Chile durante el gobierno socialista de Salvador Allende, expresaría con profundidad el nuevo compromiso político y ético de este paradigma:

\begin{abstract}
"El museo es una institución al servicio de la sociedad, de la cual es parte inalienable y tiene en su esencia misma los elementos que le permiten participar en la formación de la conciencia de las comunidades a las cuales sirven y a través de esta conciencia puede contribuir a llevar a la acción a dichas comunidades, proyectando su actividad en el ámbito histórico que debe rematar en la problemática actual: es decir anudando el pasado con el presente y comprometiéndose con los cambios estructurales imperantes y provocando otros dentro de la realidad Nacional respectiva". (Mesa Redonda de Santiago de Chile, 1972:5)
\end{abstract}

\footnotetext{
${ }^{6}$ En algunos países, como México, esta fuerte presencia indígena se plasmó en narrativas históricas y museológicas respecto de las raíces prehispánicas de la nación. (García Canclini 1989)
}

En los países de América Latina y el Caribe las experiencias se multiplicaron y tomaron distintas formas: museología comunitaria, ecomuseos, museología popular, museología social, pero fueron atravesadas por la ruptura histórica que generaron los procesos dictatoriales en el cono sur, con el consecuente negacionismo y ocultamiento de esas experiencias. A partir de los años ochenta, los caminos que cada sociedad logró realizar para el retorno a la democracia y los procesos de memoria colectiva aportaron a la recuperación de esos proyectos culturales y políticos.

En Argentina, el surgimiento y desarrollo del paradigma de la Nueva Museología no ha sido investigado de manera sistemática ni se han realizado muchas publicaciones al respecto. No obstante existieron experiencias de gran relevancia que es interesante destacar: la muestra "Tucumán Arde"7 que criticaba abiertamente el rol de los museos y tuvo trascendencia internacional; la participación de Mario Teruggi y Jorge Enrique Hardoy en mayo de 1972 en la Mesa Redonda de Santiago de Chile sobre la función de los museos en América Latina y su aporte a la construcción del concepto de "museo integral"; y la exposición "Patagonia 12.000 años de historia"8 en el ME que planteaba un debate sobre el rol social de los objetos musealizados y sobre la visión histórica del patrimonio. Todas ellas se enmarcaron en proyectos políticos y culturales, en un período de la historia del país que se caracterizó por sucesivos golpes de estado (1930, 1943, 1955, 1962, 1966, 1976), y que no daría lugar a la profundización de estas ideas, sino por el contrario, a su desaparición forzada.

En cuanto a la revisión del proceso que se dio en los museos, particularmente de historia y antropología, desde los años ochenta, no parece mostrar una relación directa, en su origen, con el Movimiento Internacional para una Nueva Museología, sino que más bien, el proceso de renovación tuvo que ver con el clima de época que reclamaba la participación de toda la sociedad en los movimientos sociales, culturales y en la reflexión histórica (Tarrago y Calvo, 2019).

\footnotetext{
7 Exposición de concepción y realización colectiva y multidisciplinaria que se presentó en noviembre de 1968 en las sedes de la CGT de los Argentinos de Rosario y Buenos Aires. Realizada por intelectuales y artistas de diferentes disciplinas, marcó un hito por su carácter vanguardista, por fuera de los circuitos tradicionales de las instituciones culturales oficiales, abordaba las problemáticas de cañeros y obreros de los ingenios tucumanos, y se constituyó como una adhesión de los artistas a las luchas populares de la época. La exhibición fue intervenida y censurada por las fuerzas represivas.

${ }^{8}$ En 1973 se inauguró en el ME la exposición Patagonia 12.000 años de historia. El guion fue publicado en el catálogo de la muestra, y se estructuraba en tres secciones: La Patagonia Prehistórica, La Patagonia a partir del siglo XVI, y Proceso de la Conquista. El discurso museológico planteaba distintos momentos de la historia de la Patagonia que fueron trascendentales en la ocupación y explotación de los recursos naturales de ese territorio: la denominada "Campaña del desierto", las prácticas genocidas implementadas por el Estado nacional contra las poblaciones originarias en el siglo $\mathrm{XIX}$, y la represión contra el movimiento obrero a principios del siglo XX (Jeria, 2016)
} 
En otras palabras, estas transformaciones que se inician con el retorno de la democracia y continúan en las décadas posteriores, se enmarcan en una serie de procesos como el reconocimiento de las demandas socioculturales del público y de las comunidades, la dinámica poblacional y demográfica, los cambios sociales vinculados a los derechos civiles y al movimiento multicultural, el acceso a la información y la revolución tecnológica, las nuevas reivindicaciones identitarias, un giro de la centralidad del objeto hacia el público, la creación de espacios de memoria, los nuevos estudios de visitantes y teorías sobre educación en museos, la concepción de responsabilidad cívica de los museos y la producción de acuerdos internacionales sobre patrimonio y museos.

\section{La redefinición del concepto de patrimonio y las políticas institucionales del Museo Etnográfico}

En ese contexto, en el ME comenzaron a definirse nuevos objetivos en tanto institución universitaria dedicada a temas de la cultura humana en general: se replantearon las exhibiciones y su papel en la sociedad local acorde al contexto histórico del momento. Podemos decir que si sus colecciones sirvieron en sus inicios para estudiar y presentar al hombre americano y la diversidad cultural y diferenciarse de los pueblos llamados primitivos y las sociedades "no occidentales", por esos años se inició un proceso de cambios, en consonancia con nuevas ideas sobre el papel de los museos en general y los antropológicos en particular con el surgimiento de nuevas identidades y el protagonismo que tomaban los pueblos indígenas en un nuevo contexto (Pegoraro, 2018).

La etapa de "reorganización integral" se inició con Alberto Rex González que asume la dirección del museo entre 1983-1986, desempeñándose el Dr. Pedro Krapovickas ${ }^{9}$ como co-director. En ese momento, la biblioteca Raúl A. Cortazar reabre sus puertas en forma irrestricta, y se reinician las visitas de público escolar para lo cual se había armado una exhibición provisoria de pueblos indígenas de Argentina en el hall central de planta baja, y del Noroeste, en la planta alta. (Pérez Gollán y Dujovne, 1995; Tarrago y Calvo, 2019).

A posteriori, se produce un cambio significativo de la mano de José Antonio Pérez Gollán y Marta Dujovne, director y secretaria académica respectivamente. En ese entonces se planteó la necesidad de prestar atención al protagonismo político que estaban adquiriendo las comunidades indígenas y que comenzaba a poner en discusión el papel de los museos como guardianes del patrimonio y del rol del estado en estas cuestiones; sobre todo se cuestionaban las formas de interpretación de la historia y el control del pasado (Podgorny y Politis, 1992). Estas discusiones implicaron una renovación conceptual que se combinó con propuestas museográficas novedosas, la innovación en materia de inventario y documentación

\footnotetext{
${ }^{9}$ (1926-1996). Director del ME en 1984
}

de las colecciones, la centralidad otorgada al Área de Extensión educativa y por ende a la definición de una política para el público, y la modernización de la conservación adecuándola a parámetros internacionales.

Esta transformación, en y del Museo, se enmarcaba en el auge de los nuevos debates sobre el patrimonio. Las relecturas de $\mathrm{P}$. Bourdieu y $\mathrm{W}$. Benjamin fueron un pivote en la producción Latinoamericana que se reflejan en una prolífica producción bibliográfica, de la mano principalmente de Arantes (1984, 1989); Bonfil Batalla (1989, 1993); Florescano (1993) y García Canclini (1989, 2010) ${ }^{10}$, entre otros.

El patrimonio comenzó a pensarse como un espacio de conflicto, de apropiación y acceso desigual. Cuando los estudios dejaron de centrarse en el sentido interno de los objetos o bienes y pasaron a ocuparse de los procesos de producción y circulación y de los sentidos que distintos receptores les atribuyen, la noción de patrimonio como acervo resultó inoperante. $Y$ se hizo evidente la desigualdad en la apropiación y reproducción cotidiana del patrimonio (García Canclini, 1989).

Entender el patrimonio como construcción social (Prats, 1997) implica reconocer las fracturas y el conflicto tanto en su proceso de definición, en las políticas de conservación, como en la relación de los habitantes de una nación con él. Por lo tanto, la construcción del patrimonio pasa a pensarse como una operación dinámica enraizada en el presente a partir de la cual se reconstruye, selecciona e interpreta el pasado.

Como parte de estas discusiones, el proyecto del museo (Pérez Gollán y Dujovne, [1987] 1997) procuraba romper con la visión de un patrimonio nacional hegemónico y dar lugar a considerar las concepciones del mundo de los sujetos que son sus protagonistas y que habían sido excluidos históricamente de la historia nacional y del discurso del museo. Se hizo necesario revisar la historia de los pueblos indígenas y sus procesos de transformación social hasta la actualidad, reconocer el estado actual de sus derechos y reclamos, la dinámica identitaria y las políticas culturales en torno a estos pueblos y sus patrimonios, entre muchos otros temas. Se abrieron así, nuevos interrogantes y perspectivas sobre la representación de culturas y sociedades.

En este sentido, el proyecto general del ME se propuso como uno de sus objetivos primordiales abordar la diversidad multiétnica y pluricultural que caracteriza a nuestra sociedad, como parte de los procesos sociales e históricos que dieron origen a la nación y revalorizando su

\footnotetext{
10 Una síntesis de las perspectivas teóricas latinoamericanas se puede ver en, Benedetti, Cecilia. (2004) "Antropología social y patrimonio. Perspectivas Teóricas latinoamericanas", en Rotman, M. (editora Responsable). Antropología de la cultura y el patrimonio. Diversidad y desigualdad en los procesos culturales contemporáneos, Ferreyra editor, p.15-26.
} 
contribución actual. Más aún hoy, siglo XXI, lo patrimonial se continúa complejizando, se amplía y democratiza a partir del empoderamiento de grupos que elaboran su diferencia discursiva y simbólicamente en torno a distintas categorías identitarias -étnicas, género, etc.-

\section{El Museo Etnográfico y la Revista RUNA ${ }^{11}$}

Este conjunto de transformaciones conceptuales y museográficas que comienzan a gestarse en los museos a nivel general y en el ME en particular, quedan en parte reflejadas, en el balance de gestión publicado por J. Pérez Gollán y M. Dujovne en el Volumen 22 (1995) de la Revista RUNA. Sin embargo, la publicación de ese trabajo, incluido además en toda una sección dedicada a "Ferias y Museos", está vinculada por un lado al devenir propio y los objetivos de la Revista en esa etapa y por otro a las relaciones personales e intereses de quienes fueron responsables de la RUNA y del Museo en ese entonces.

RUNA apareció por primera vez en 1948 y estaba dirigida por José Imbelloni, quien por ese entonces había reemplazado a Francisco de Aparicio como Director del ME y además se desempeñaba como director del Instituto de Antropología de la Facultad de Filosofía y Letras, fundado un año antes. La revista surge en un momento particular de la disciplina antropológica en Argentina, vino a sustituir a las series editadas como: "Publicaciones del Museo Etnográfico" y marcó "un cambio radical en la vida institucional del Museo Etnográfico", que al pasar a ser anexo del Instituto de Antropología, enfatizó su rol como centro universitario de docencia e investigación en detrimento de su función museográfica (RUNA, 1990). Al respecto de esto, dice Imbelloni:

"El hecho que con la salida de RUNA quedan interrumpidas las Publicaciones del Museo Etnográfico, no debe atribuirse, sin embargo, a la renovación de propósitos y métodos que acabamos de ilustrar, y tanto menos a un desconocimiento de los meritorios trabajos allí publicados, sino a la circunstancia que la fundación del Instituto de Antropología ha dejado sin efecto aquella intitulación." (Imbelloni, 1948).

En efecto, RUNA se vinculó al ME de diferentes maneras desde su origen hasta su interrupción en la década del 70. El Museo funcionó por momentos como editor y distribuidor $y$, en otros, como un espacio más de almacenaje de sus volúmenes impresos o de recepción de

\footnotetext{
11 Gran parte de este artículo surge de las discusiones en torno a la realización del Dossier por los 70 años de la Revista Runa. Este acápite recorre una parte de la relación de la Revista con el Museo y da cuenta de los vínculos entre la Exhibición en cuestión, el proceso de re-apertura y re-organización del Museo y la relación con Runa en ese entonces.
}

otras publicaciones por canje. Por ejemplo, en el archivo administrativo de la Biblioteca del ME, están registrados todos los ejemplares de la Revista RUNA enviados a diferentes instituciones y editores de otras publicaciones, hasta el volumen 11 (publicado en 1968) ${ }^{12}$.

A través de estos intercambios, la revista le permitió al Museo no sólo difundir las investigaciones de los antropólogos locales sino también acrecentar el acervo de su Biblioteca y poner en acceso público ediciones de otros museos, universidades y espacios académicos ${ }^{13} \mathrm{en}$ sus salas de consulta.

Es interesante destacar que, aunque entre el volumen 12 (1970) y el 19 (1990) la participación del Museo parece desaparecer de la edición y distribución de la revista, en algunas ediciones aún consigna su dirección postal como receptora de canjes.

Ahora bien, en la publicación de 1990, el Museo concebido como "como institución de difusión encargada de transferir los conocimientos generados en la Universidad" vuelve a involucrarse con RUNA, y desde la Nota editorial se plantea su coincidencia con una nueva etapa de la Revista en la que ambos buscan diversificar sus temáticas:

"Se manifiesta un interés por encarar
el trabajo y los desafíos de manera
conjunta que deriva en una dirección
de la Revista compartida por el Instituto
y el Museo. En esta nueva línea se
proyecta realizar números temáticos
que den cuenta de la renovación de
la disciplina y que permitan debatir y
analizar "[...] problemas cruciales del
campo antropológico -en su más
amplio sentido-, buscando el cruce
entre las diferentes especificidades
y las diversas perspectivas teóricas y
metodológicas" (1990:8).

Otro punto de coincidencia manifestado en este número es la preocupación por abordar la historia disciplinar y, en consecuencia, difundir y resguardar la documentación vinculada a su investigación. El artículo de Patricia Arenas (1990) plantea la importancia de la correspondencia como fuente. El trabajo con las dos cartas presentadas (una escrita por Samuel Lafone Quevedo y otra enviada por José Imbelloni a Eric Boman) fue resultado del "Taller de

\footnotetext{
12 Com. Per. Eduardo Jopia. Jopia es Licenciado en Historia de la Facultad de Filosofía y Letras, y trabaja en dicha casa de estudios, como personal Nodocente desde 1977. En el ME desempeña tareas en la Biblioteca "Raúl Cortazar" desde 1983.

13 Incluso en la actualidad, como herencia de dichos canjes, el Museo sigue recibiendo las publicaciones del "Journal de la Société des Americanistes", du siege de la société Musée du QuaiBranly, de Paris, Francia y el "Boletín del Museo de Arte Precolombino", del Museo de Arte Precolombino de Santiago de Chile, Chile.
} 
Historia de la Antropología" realizado en el ME y que inició la catalogación de la documentación que hoy conforma el Archivo Fotográfico y Documental.

El número siguiente es una iniciativa editorial conjunta de la Comisión organizadora del III Congreso de Antropología Social, el ICA y el Museo. Tanto en las "Palabras Previas" de Edgardo Garbulsky como en el prólogo de Pérez Gollán (en ese entonces director del Museo), se destacan dos aspectos: el contexto de revisión de la práctica, la teoría y el campo de la antropología argentina y la importancia de generar espacios de debate, como el Congreso y el Simposio "Historia de la Antropología en Argentina y Latinoamérica"14.

El Museo y sus exhibiciones, lejos de ser considerados neutrales o inmutables, se configuran como uno de los campos antropológicos donde consolidar y difundir esas discusiones. Según Pérez Gollán, el Museo:

"[...] comparte con el Instituto la responsabilidad editorial de RUNA. Esta última circunstancia marca la existencia de un proyecto para poner el Museo a la altura de los imperativos de la antropología moderna en la que la difusión editorial y la transferencia de conocimientos ocupan un lugar de privilegio. Además, pone el acento en la necesidad de agrupar los esfuerzos de quienes trabajan en el dilatado campo antropológico" (1992:9).

En esta etapa de confluencia, el número 22 (1995) de RUNA dedicó una sección completa a "Museos y ferias" en la cual se publica "El Museo Etnográfico de la Facultad de Filosofía y Letras: balance de una gestión".

En el artículo, Pérez Gollán y Dujovne ubican el proyecto de reformulación institucional del ME en el contexto más amplio de discusión acerca de los objetivos, funciones y métodos de los museos en el mundo y las transformaciones sufridas por el concepto mismode patrimonio. $Y$ proponen una noción de museo, cuyas funciones son investigar y difundir o comunicar el patrimonio cultural utilizando como instrumento privilegiado de acción la exposición de objetos.

La publicación misma del artículo se presenta como parte integral de las acciones del nuevo proyecto de Museo, en lo que refiere a su papel como espacio de investigación ${ }^{15}$.

\footnotetext{
14 Este Simposio y el Taller asociado fueron estimulados por el desarrollo del "Taller de Historia de la Antropología" realizado en el Museo por Laura Piaggio y Elena Ramoninicon el apoyo de la Fundación Antorchas (Pérez Gollán, 1992:9). Ver Piaggio, L. (1992) Fotos, historias, indios y antropólogos En Runa Vol. 20 (pp. 163-167)

15 Los autores diferencian los tipos de investigación que son necesarias al interior de un museo universitario disciplinar, y tipifican: Investigaciones necesarias para una investigación; Investigaciones que utilizan el acervo del Museo para estudiar materiales o para
}

A la par, define las características y lineamientos básicos de los procesos de conservación, recuperación, protección, difusión y comunicación que deben realizarse en los museos universitarios. Y, como propone su título, rescata las acciones realizadas desde 1987 hasta ese momento, haciendo énfasis en los trabajos simultáneos de adecuación edilicia, catalogación e investigación de colecciones, difusión ${ }^{16}$ y, principalmente, las acciones de recuperación del Archivo fotográfico y documental del Museo y el proyecto de conservación de textiles andinos.
"[...] solo cuando hayamos valorizado las distintas funciones del museo garantizando su articulación, podremos considerar satisfactorio el resultado: conformar un museo universitario digno de ese nombre, que investigue y difunda, profundice conocimientos y los transfiera a la comunidad" (Pérez Gollán y Dujovne, 1995:131).

Este breve recorrido pone de manifiesto que, aunque a lo largo de la historia de RUNA se encuentran trabajos que analizan colecciones específicas ${ }^{17}$ o abordan problemáticas de las disciplinas a partir del acervo; en este período, la institución museo aparece como un objeto de reflexión antropológica e histórica, y sus integrantes se muestran comprometidos con los debates que las articulaban con la museología.

\section{Del Proyecto de Museo a las nuevas exhibiciones}

En términos generales el Proyecto para el ME de Pérez Gollán y Dujovne (1995) procuró imprimir un sello distintivo: exhibiciones que den cuenta de la dinámica del patrimonio y mostrar, desde una perspectiva histórica, social y cultural, una etapa casi ignorada en el discurso histórico oficial: la de los pueblos originarios y la existencia de sociedades complejas con anterioridad a la llegada de los españoles.

El desafío del Museo era mostrar la profundidad del pasado, la diversidad cultural y la complejidad histórica y priorizar la representación dinámica de la historia de las poblaciones indígenas de la Argentina. La elaboración de guiones con énfasis en la dimensión histórica de la explicación social, intentaba discutir la división entre pueblos civilizados e incivilizados o pueblos sin historia,

investigaciones culturales más amplias; Investigaciones tecnológicas sobre los materiales mismos; Investigaciones históricas sobre la propia institución; Investigaciones sobre la función pedagógica del Museo (Pérez Gollán y Dujovne, 1995)

16 Se constituye un área de museografía, se trabajan guiones conceptuales para las exhibiciones y se refaccionan y reacondicionan las salas, se concretan exposiciones temporarias, entre otras.

${ }^{17}$ A modo de ejemplo ver: Cordeu, J. (1986). Los atuendos Shamánicos chamacoco del Museo Etnográfico: un intento de interpretación simbólica: Runa, 26. 103-139. 
y con ello sentar las bases para pensarnos como una sociedad multiétnica y pluricultural (Pérez Gollán y Dujovne, 1995, 2001). Esta mirada de los procesos sociales se construyó a través de la discusión y el análisis interdisciplinario en la elaboración de los guiones de las exhibiciones.

\section{"Desafiando al silencio: pueblos indígenas y dictadura" 18}

El recorrido histórico conceptual que hemos realizado hasta acá intenta poner de relieve que estos cambios acontecidos al interior del Museo no fueron lineales ni sucedieron todos juntos. Es menester aclarar que el contexto político, económico e ideológico de la segunda mitad de 1980 era particularmente diferente al que existía en 2016 cuando se gestó esta exhibición y el lapso de tiempo que separa a estos contextos permitió que muchas de las discusiones que mencionamos, y otras nuevas que surgieron, se asentaran, se resignificaran e hicieran parte constitutiva de la política institucional del ME.

Sobre los logros en materia de DDHH en nuestro país, debemos destacar que durante la misma dictadura se iniciaron las denuncias de sobrevivientes por secuestros y desapariciones, surgieron organizaciones de gran importancia como Madres y Abuelas de Plaza de Mayo, y se fue conformando una resistencia social-compuesta principalmente por organismos de derechos humanos y sectores de la clase trabajadora-, que marcaría un camino hacia la recuperación de la democracia en 1983. La década del ochenta estuvo signada por distintos hitos: la creación de la Comisión Nacional sobre la Desaparición de Personas (CONADEP, 1983), el juicio a las juntas (1985), el inicio de los juicios a represores, y los procesos de memoria para reconstruir lo sucedido. Pero también por los juicios a integrantes de las organizaciones revolucionarias, los alzamientos carapintadas (1987-1990), las leyes de punto final (1986) y obediencia debida (1987), y los indultos (1989-1990). En todos esos años, el pueblo argentino y sus organizaciones de derechos humanos nunca dejaron de luchar. Para la década del noventa, al cumplirse veinte años del golpe de 1976, se multiplicaron las experiencias de construcción de memoria social e histórica, y ocurrieron hechos que marcarían las décadas siguientes: la creación de H.I.J.O.S., los juicios a los genocidas en el extranjero, el surgimiento de organizaciones sociales y movimientos de trabajadore/as desocupados, la rebelión popular de 2001, todas experiencias que enfrentaron las políticas del neoliberalismo, acompañadas por las cada vez más multitudinarias movilizaciones que se realizan cada año el 24 de marzo.

\footnotetext{
18 Esta exhibición fue realizada con la participación de casi todas las áreas de trabajo del ME: Acción Cultural, Archivo, Arqueología, Biblioteca, Conservación y Museografía, Curaduría y Diseño, Etnografía, Extensión Educativa, Prensa, Mantenimiento y Servicios Generales. Para acceder a la gacetilla de prensa de su inauguración ir a: https://issuu.com/etnoba/docs/dossier_prensa
}

Por otra parte, en 1994 se produjo la Reforma Constitucional, que reconoció la preexistencia de los pueblos originarios y sus derechos en el marco de la incorporación del Convenio 169 de la OIT; y que determinó la jerarquía constitucional de los tratados internacionales sobre derechos humanos. Es decir, se ampliaron derechos y garantías.

En 2003 se aprobó en la Cámara de Diputados la ley que declaró nulas las leyes de obediencia debida y punto final, y fue promulgada por el entonces presidente Néstor Kirchner. En 2005 la Corte Suprema de Justicia de la Nación emitió un fallo declarando inconstitucionales las leyes de impunidad, y se profundizó en Argentina un proceso histórico de relevancia internacional para el juzgamiento de crímenes contra la humanidad, permitiendo que cientos de represores fueran condenados por su accionar durante el terrorismo de estado.

En cuanto a la irrupción de esta temática en el ámbito de los museos y espacios patrimoniales, ya a finales de los años ochenta se empezó a pensar y proyectar ideas para un museo de la memoria. En los noventa se desarrollaron proyectos como el Sitio de Memoria Atlético (1996), el Sitio de Memoria de Mansión Seré (1997), el Parque de la Memoria (1998), el Museo de la Memoria de Rosario (1998), entre otros. Hoy existen en Argentina más de cuarenta Espacios para la Memoria, ciento sesenta señalizaciones de lugares donde funcionaron centros clandestinos de detención, tortura y exterminio, y la Ley 26.691 de Sitios de Memoria (2011), que dan cuenta de un largo proceso de patrimonialización de la historia reciente.

En el marco del $\mathrm{ME}$, se registran tres experiencias como antecedentes (Jeria, 2016):

1) la participación de las especialistas en arqueología del ME Adriana Callegari y Mónica Berón en el seminario de actualización de técnicas forenses organizado en 1985, a instancias de la CONADEP y la organización Abuelas de Plaza de Mayo ${ }^{19}$. Se estudiaron casos que sirvieron como prueba en el Juicio a las Juntas en 1985.

2) El apoyo del Dr. Alberto Rex González a la conformación del Equipo Argentino de Antropología Forense mientras fue director del ME.

3) En marzo de 2009, el ME organizó en su sede la Semana de la Memoria y desarrolló una exposición con las fotos de 26 estudiantes y docentes de la carrera de Antropología detenidos desaparecidos o asesinados por la dictadura. Esas imágenes eran parte de los legajos universitarios abiertos por la Cátedra Libre de DDHH y la

\footnotetext{
19 Solicitaron la asistencia del Programa de Ciencia y Derechos Humanos de la Asociación Americana para el Avance de la Ciencia. Los docentes fueron los doctores Clyde Snow, R. Kirshner, L. Levita y J. Fitzpatrick. Tuvo lugar en la Facultad de Medicina-UBA, con el apoyo de la Subsecretaría de Derechos Humanos de la Nación.
} 
Secretaría de Extensión FFyL-UBA, y digitalizados por el equipo Construyendo Memoria.

En síntesis, esta exhibición retoma ese recorrido histórico y surge en una coyuntura nacional e internacional específica de las ciencias sociales y humanas que atraviesa a los museos antropológicos y al ME en particular.

La exhibición nace como una iniciativa del equipo del $\mathrm{ME}$, interesado en que la institución se posicione en los debates públicos en torno al cuarenta aniversario del golpe de estado de 1976. Bajo la Dirección de las Dras Mónica Berón ${ }^{20}$ y Andrea Pegoraro ${ }^{21}$, y en el marco de una creciente participación social y de políticas públicas en las temáticas de la historia reciente y el proceso de Memoria, Verdad y Justicia, en el Museo se plantearon dos ejes a abordar: las implicancias para la comunidad universitaria y las comunidades indígenas.

La recuperación de la memoria sobre la acción dictatorial en la universidad se inició en la Facultad de Filosofía y Letras a mediados de los años noventa y ese trabajo se profundizó a partir del treinta aniversario del golpe. Por otro lado, al comenzar a pensar cómo fue el accionar represivo de la dictadura sobre los pueblos indígenas, encontramos un desafío: retomar los trabajos existentes y reunir nuevas colecciones para abordar un período que no era considerado en el relato del museo. Esto nos llevó a indagar el papel de estos grupos en aquellos años y la forma en que la dictadura actuó sobre ellos.

En una primera etapa, en marzo de 2016 se inauguró una pequeña muestra con dos vitrinas. Bajo el título "Desafiando al silencio: Pueblos indígenas y dictadura" se exhibían algunos objetos de la colección del Museo, objetos no patrimoniales comprados especialmente, documentos y gráfica, organizados en ejes que dieron luego origen al proyecto de exposición ampliada. Esta primera muestra fue realizada por el equipo de trabajo del ME con el asesoramiento científico de investigadores ${ }^{22}$ de la Red de Investigadores sobre Genocidio y Política Indígena en Argentina, de la Sección Etnohistoria (ICAFFyL) y del equipo de Antropología Política y Jurídica (FFyLUBA). La repercusión que tuvo fue de gran importancia: participaron más de cien personas en la actividad de inauguración y despertó interés en distintos ámbitos superando las expectativas del Museo. Por primera vez se abordaba en una muestra la identidad indígena de los/ las detenidos/as desaparecidos/as.

A partir de esas acciones, de la información que fuimos relevando y recibiendo, del interés que generó el tema, de su vacancia en los museos de antropología y de historia,

\footnotetext{
${ }^{20}$ Dra. En Ciencias Antropológicas, Directora del ME desde 2015.

21 Dra. En Ciencias Antropológicas-FFyL-UBA. Secretaria Académica

22 En la primera etapa participaron Diana Lenton, Marcelo Musante, Santiago Garaño, María Sol Ottini, Luciana Mignoli y M. Victoria Pierini. Luego sumaron sus aportes, entre otros, Carlos Bartolomé, Andrés Servin, Nidia Buttori y Delia Maisel.
}

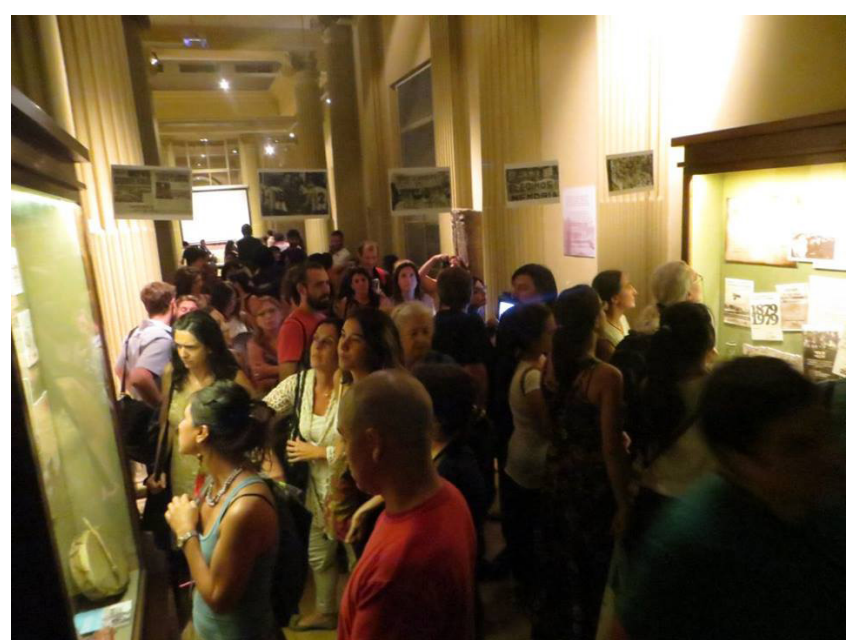

Figura 1. Crédito: Área de Conservación y Museografía, Museo Etnográfico FFyL-UBA Inauguración de la exhibición Desafiando al Silencio: pueblos indígenas y dictadura en el Museo Etnográfico FfyL-UBA, marzo de 2016.

Figure 1. Credit: Conservation and Museography Area, Ethnographic Museum FFyL-UBA. Opening of the exhibition "Challenging silence: indigenous peoples and dictatorship" at the Ethnographic Museum FfyL-UBA, march 2016.

y dado el contexto nacional adverso y persecutorio hacia las comunidades indígenas, surgió la idea de ampliar esta primera experiencia en un proyecto de exposición para la sala central del ME.

El proyecto de esta exhibición puso de manifiesto el posicionamiento institucional como Museo:

"Recordar y visibilizar lo sucedido
durante las décadas del 70 y 80 nos
remite a reflexionar sobre la violencia
del estado, la resistencia, las ausencias,
los silencios y las demandas de justicia.
El de 1976 no fue el único golpe
de estado en el siglo XX: en 1930,
1943, 1955, 1962 y 1966 también
se instauraron dictaduras cívico-
militares en el país. El autodenominado
"Proceso de Reorganización Nacional"
de 1976 fue un proceso genocida que
dejó una marca aún más profunda
en la sociedad y utilizó el terrorismo
de estado para imponer cambios
políticos, económicos y culturales.
Para llevar adelante su proyecto,
esta dictadura hizo desaparecer a
30.000 personas. ¿Quiénes eran?
Hombres y mujeres. Niños, jóvenes
y viejos. Estudiantes y trabajadores,
de la ciudad y del campo. Personas
con diversas identidades políticas,
sindicales, estudiantiles, sexuales, 
étnicas, etc. La mayoría de ellos eran parte de organizaciones y espacios que buscaban transformaciones profundas en la sociedad: luchaban contra la opresión y la explotación. [...] Los pueblos originarios del actual territorio argentino no estuvieron ajenos a esta historia. El 24 de marzo de 2016 cientos de miles de personas se movilizaron en todo el país en repudio al golpe y expresaron su compromiso con las consignas de Memoria, Verdad y Justicia.

Nos interesa presentar ideas y reflexiones sobre la situación de los pueblos originarios y sus organizaciones en las décadas del 60 y 70 , indagar cuáles fueron las acciones de la última dictadura sobre ellos y recordar a las víctimas del terrorismo de estado y sus reivindicaciones. Y esto supone presentar a este colectivo -los pueblos indígenas- como un actor político económico relevante de la historia reciente de la región y poner en cuestión la imagen cristalizada que suele ligarlos a un pasado remoto."(Jeria y Stáffora, 2016)

Desde la curaduría, nos propusimos trabajar durante los siguientes meses en la investigación, en el relevamiento de nuevos materiales, realización de entrevistas, incorporación de nuevas tipologías de objetos, desarrollo de instancias de participación y consulta. Esta experiencia estuvo enmarcada en las teorías de la museología social y la museología de ruptura (Chagas, 2014; Hainard, 2007) y en las prácticas que se vienen desarrollando a nivel institucional y profesional con diversos públicos y comunidades.

Nos planteamos como objetivos:

- Aproximar a los visitantes a las temáticas vinculadas al Terrorismo de Estado implementado en la Argentina durante las décadas del 70 y 80, a la desaparición forzada de personas y a sus consecuencias en la sociedad argentina y especialmente en los pueblos indígenas.

- Dar cuenta de la participación y organización política reciente del movimiento indígena en Argentina.

- Reconocer la diversidad de contextos geográficos en los cuales se produjo el terrorismo de estado.

La filosofía del MINOM ${ }^{23}$, como corriente internacional

${ }^{23}$ Movimiento Internacional para la Nueva Museología, MINOM de referencia para la Nueva Museología, fue importante para esas definiciones, dado que presenta al museo como una herramienta "para combatir la injusticia, fomentar el desarrollo en las comunidades, fomentar el diálogo"24 y propone pensar las prácticas museológicas en torno a los/as sujetos/as y no a los objetos. Por otro lado, la museología social -que se expresa como una corriente que sólo se puede desarrollar en un vínculo con y para la sociedad o la comunidad de pertenencia- fortalece la reflexión conceptual sobre la historia del ME y su relación con los pueblos indígenas en distintos períodos del siglo XX. Desde esta perspectiva, los museos que sirvieron para preservar los objetos preciados de las clases dominantes y fueron construidos y utilizados por los estados nacionales como dispositivos ideológicos para disciplinar el pasado, el presente y el futuro social; encaran hoy procesos de democratización y resignificación que incorporan colectivos comúnmente denominados como subalternos o minorías (de clase, étnicas, sexuales, religiosas, lingüísticas, etc.).

A través de "Desafiando al silencio" abordamos un problema social de amplio desarrollo: las prácticas genocidas y la desaparición forzada de personas. En el siglo XXI, tras décadas de lucha de sobrevivientes, familiares y organizaciones de derechos humanos, se constituyó una política pública nacional de Memoria, Verdad y Justicia que, sin embargo, no incluía las problemáticas y experiencias de los pueblos indígenas como sujetos específicos víctimas de la represión dictatorial.

El guión curatorial se enfocó en dos líneas principales: la organización (comunitaria, política, sindical, social, cultural) indígena en Argentina en los 60 y 70, y las prácticas de violencia estatal que afectaron a las comunidades en la dictadura.

Estudiamos e investigamos durante varios meses ${ }^{25}$, compartiendo con un equipo de trabajo activo y con diversos grupos y personas, de manera cooperativa y constructiva, sostenidas en la idea de Hainard sobre el rol de los museos:

Cuando afirmo que el museo de etnografía

\footnotetext{
${ }^{24}$ Filosofía del MINOM, http://www.minom-icom.net/about-us

25 Se consultaron 19 archivos y organizaciones para la selección de documentos, imágenes, objetos. (Archivo de la Asociación de Ex Detenidos Desaparecidos; Archivo Nacional de la Memoria; Archivo de Artista "Juan Carlos Romero"; Archivo Hasenberg-Quaretti; Archivo La Gaceta de Tucumán; ARGRA - Asociación de Reporteros Gráficos de la República Argentina; CEDINCI - Centro de Documentación e Investigación de la Cultura de Izquierdas en Argentina; Contrapunto Prensa Alternativa de Tucumán; CTERA - Instituto de investigaciones Pedagógicas "Marina Vilte"; Fundación Pluma; Grupo Investigación Genocidio en Tucumán; Liceo 9 DE 10, Caba; Movimiento Ecuménico por los Derechos Humanos; Museo Histórico Municipal de Baradero; Museo Histórico Reg. L. Vintter, Gral Roca, Río Negro; Museo Municipal de Aluminé, Neuquen; Museo Participativo Minero; Ruinas Mágicas; Sitio de memoria ex CCDTyE "Club Atlético")
} 
debería ser, hoy, un lugar de deconstrucción cultural, quiero decir que ante todo deberíamos saber cómo pensamos, describir nuestro funcionamiento, descubrir la forma en que construimos nuestros estereotipos y nuestras ideologías. Así podemos entender cómo hemos mirado a los demás". (Hainard, 2007)

Nos sumergimos a leer sobre la creación de organizaciones indígenas locales y federaciones nacionales e internacionales, realización de parlamentos y encuentros de formación, el trabajo con algunos sectores religiosos y organizaciones sociales, la participación en movimientos políticos y partidarios, la creación de redes y cooperativas de productores y la redacción de proyectos de legislación nacional.

Reunimos testimonios y producciones teóricas que dan cuenta de la persecución a los pueblos indígenas por los reclamos culturales, económicos, territoriales y sociales que sostenían sus organizaciones comunitarias y sus otros espacios de participación (sindicatos, partidos políticos, organismos estatales, etc.) durante la última dictadura. Identificamos que las listas oficiales no dan cuenta de la pertenencia étnica de las víctimas del terrorismo de estado, pero que sabemos por investigaciones, testimonios y declaraciones judiciales que hubo indígenas secuestrados en centros clandestinos de detención o cárceles, desaparecidos o que sufrieron el exilio interno y externo.

Abordamos diversas historias de vida ${ }^{26}$, dando cuenta de las biografías (Camarena Ocampo, et. al. 1994) como herramienta de transmisión y de identificación, y relatamos las historias de Celestino Aigo, Abelardo Coifin, Juan Raúl Pichulmán, José Francisco Pichulmán, Pedro Santana, Avelino Bazán, Marina Vilte, Jesús Costilla, Eulogio Frites y Nilo Cayuqueo ${ }^{27}$.

Dimos cuenta de diversas formas de memoria: sus rostros y reclamos reaparecen hoy en murales en sus barrios, en las fotografías que sostienen sus familiares en las manifestaciones y en los testimonios en los juicios a los militares responsables de desapariciones y torturas.

Nos adentramos en las historias sobre el poder desaparecedor (Calveiro 1998) de los ingenios azucareros, evidenciando la alianza entre poder económico y fuerzas militares, que se fortaleció durante la última dictadura. Numerosas empresas, entre ellas los ingenios, se comprometieron con la represión: aportaron sus propios recursos, dieron información sobre los trabajadores y hasta facilitaron sus predios para instalar centros clandestinos de detención. Entre 1974 y 1978, fueron secuestrados

\footnotetext{
${ }^{26}$ Para profundizar sobre las historias de vida ver: Lenton 2014 y 2015.

27 Víctimas del terrorismo de estado, con filiación indígena según consta en relatos de familiares, amigxs y/o compañerxs, y en documentos de la época.
}

al menos veinticinco obreros del Ingenio Concepción (Tucumán), veinticinco del Ingenio La Fronterita (Tucumán) y sesenta del Ingenio Ledesma (Jujuy). En los vehículos de la empresa Ledesma se detuvo a más de cuatrocientos militantes populares de Libertador General San Martín y Calilegua durante la "Noche del apagón" en julio de 1976. Treinta de ellos permanecen desaparecidos.

Preguntamos ¿De quién es el pasado? y mostramos los intentos de apropiación de la historia de los Valles calchaquíes por parte del Ejército, cuando en 1977 el gobierno de facto de Tucumán decidió reconstruir el llamado "sitio arqueológico de Quilmes" (hoy Ciudad Sagrada) con fines turísticos. Para hacerlo, no se tuvieron en cuenta criterios de investigación arqueológica ni de conservación patrimonial. En diciembre de 1980 se inauguró el museo de sitio resaltando el pasado heroico y guerrero de los Quilmes, mientras se ocultaba su presente y se perseguía a sus integrantes. Los terratenientes cobraron por la expropiación de las tierras que la comunidad reclamaba como propias (Becerra et. al., 2013; Sosa, 1997).

Finalmente, hablamos de genocidio (Feierstein, 2007). En junio de 1979 se cumplieron 100 años de la denominada Campaña al Desierto encabezada por Julio A. Roca. El gobierno militar celebró el centenario con homenajes, medallas, estampillas y monedas conmemorativas. En pleno conflicto político-territorial con Chile, el acto oficial en la ciudad de Neuquén presentó como una "gloriosa y trascendente gesta de todos los argentinos" el proceso de despojo y matanza indígena de 1879. El propio ME se plegó a esta conmemoración tal como aparece en el discurso de su director incluido en la exhibición.

Pensamos el guión de la exposición con el concepto de museo diccionario de la museología de ruptura (Hainard, 2007), donde los objetos son las palabras y construimos una observación, un discurso, un relato contado con esos objetos. Exponer equivale a contar historias. En ese camino, nos encontramos con ausencias materiales. Las colecciones que alberga el ME representan un período temporal que no supera la primera mitad del siglo $X X$. Por diversas razones (disciplinares, políticas, económicas, etc.) las colecciones no se han incrementado a partir de esa fecha y, por tanto, no es posible dar cuenta del pasado reciente sólo con el patrimonio institucional. La compra y las donaciones de objetos de las décadas del sesenta y el setenta fue desarrollada en vinculación con las reflexiones de la museología de ruptura nacida y crecida en Neuchatel, Suiza, con el trabajo de Hainard y su equipo: "para hacer nuestras exposiciones, para explicar nuestras historias, siempre habíamos necesitado objetos de la sociedad actual. [...] todo objeto que entrara dentro del museo debía recibir el mismo trato que los demás." (Hainard, 2007).

La selección de las piezas expuestas incluyó una diversa 


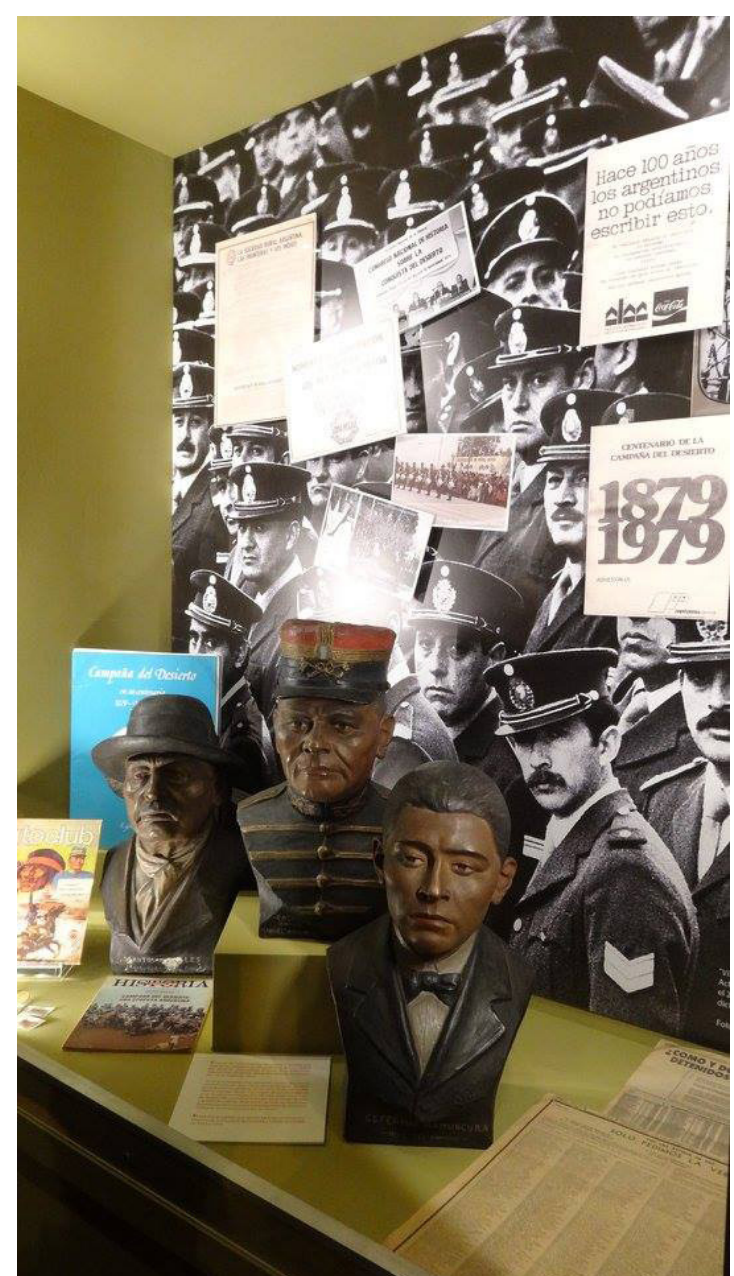

Figura 2. Crédito: Área de Conservación y Museografía, Museo Etnográfico FfyL-UBA Vitrina "Dos siglos, dos genocidios", exhibición Desafiando al Silencio: pueblos indígenas y dictadura en el Museo Etnográfico FfyL-UBA.

Figure 2. Credit: Conservation and Museography Area, Ethnographic Museum FfyL-UBA Exhibit case "Two centuries, two genocides", exhibition "Challenging silence: indigenous peoples and dictatorship" at the Ethnographic Museum FfyL$U B A$.

variedad de prácticas: uso de colecciones del museo, préstamos personales, de otros museos, instituciones públicas y privadas, donaciones, compras de materiales contemporáneos, y una convocatoria pública ${ }^{28}$ vía redes sociales invitando a la participación y solicitando ciertas piezas específicas en préstamo.

Durante todo este proceso, nos hicimos muchas preguntas. Algunas vienen acompañando nuestras

\footnotetext{
${ }^{28}$ A través de esta convocatoria y de contactos personales se recibieron en préstamo objetos como ejemplares de la revista "El Descamisado", útiles escolares o un tocadiscos. Otros materiales relevantes para el relato museográfico, en cambio, surgieron de relaciones institucionales como un casco del Museo Participativo Minero o un pico del ex CCDTyE "Club Atlético". Estas prácticas reflejan, a la vez, la importancia de los vínculos para el desarrollo de esta exhibición y los límites del acervo del Museo para abordar realidades más recientes.
}

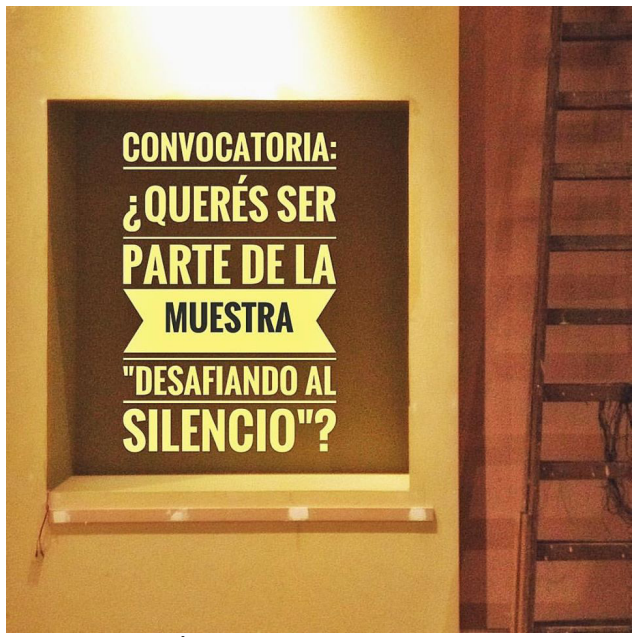

Figura 3. Crédito: Área de Acción Cultural, Museo Etnográfico FfyL-UBA Afiche de convocatoria pública a préstamo de objetos y documentos para la exhibición Desafiando al Silencio: pueblos indígenas y dictadura en el Museo Etnográfico FfyL-UBA, 2016.

Figure 3. Credit: Cultural Affairs Area, Ethnographic Museum FfyL-UBA Poster of public call for loan of objects and documents for the exhibition exhibition "Challenging silence: indigenous peoples and dictatorship" at the Ethnographic Museum FfyLUBA, 2016.

prácticas y experiencias desde hace varios años: ¿Cómo ampliar la participación de actores externos a la institución en los relatos museológicos? ¿Cómo desarrollar exposiciones que abran un diálogo hacia el presente? Como institución hemos transitado diferentes formas de organización y de vinculación con la sociedad, de acuerdo a los contextos históricos de los cuales fuimos y somos parte y resultado.

Hoy conformamos un museo en movimiento, interesado en promover la participación y en desarrollar una museología que aporte herramientas para la articulación patrimonio-comunidad. Entendemos que estos dos pilares contribuyen a la construcción de espacios democráticos y al ejercicio pleno de los derechos culturales. En este sentido suscribimos a los conceptos de la Declaración del Primer Encuentro Iberoamericano de Museos (2007); definiendo la participación con los preceptos de la Carta Cultural Iberoamericana (2006) y con distintos niveles de profundidad como propone Malena Bastías (2013) ${ }^{29}$.

Estas ideas dan soporte a diferentes experiencias desarrolladas en las últimas dos décadas para ampliar la participación de diversos sectores sociales tanto en actividades públicas como en proyectos vinculados a las colecciones del Museo. En el caso de esta exhibición, el relato no se construyó de manera unilateral sino que consultamos a un grupo de asesores científicos

\footnotetext{
29 Bastías enumera los niveles de participación que una institución puede asumir: Informando, Consultando, Decidiendo juntos, Actuando juntos y Apoyando a otros que toman la iniciativa.
} 
Figura 4. Crédito: Área de Conservación y Museografía, Museo Etnográfico FfyL-UBA Vitrina "Historias de vida", exhibición Desafiando al Silencio: pueblos indígenas y dictadura en el Museo Etnográfico FfyL-UBA.

Figure 4. Credit: Conservation and Museography Area, Ethnographic Museum FfyL-UBA Exhibit case "Life stories", exhibition "Challenging silence: indigenous peoples and dictatorship" at the Ethnographic Museum FfyL-UBA.

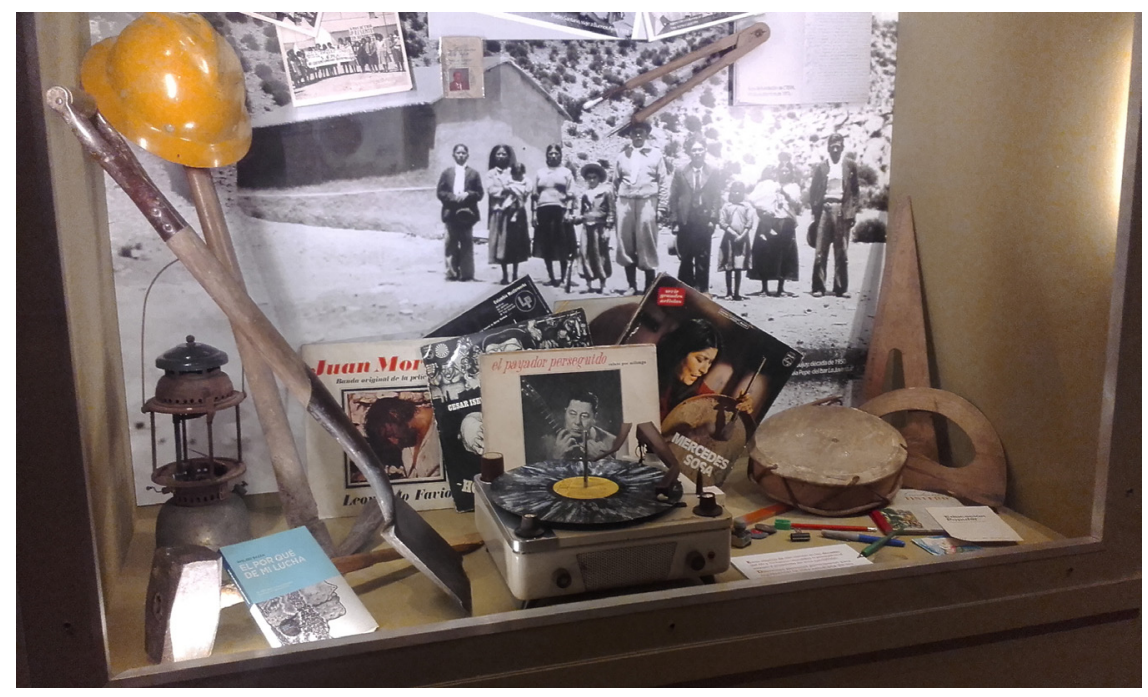

y testimoniales que sumaron sus saberes de manera generosa y comprometida. ${ }^{30}$ Nos reunimos con Nilo Cayuqueo, quien participó en estos procesos históricos de organización indígena, para conocer su experiencia, conversar y consultarlo acerca del relato y el tipo de objetos en que pensábamos sostenerlo. También nos acercamos a Francisco Chaile, cacique de la Comunidad Indígena Quilmes de Tucumán, y nos comunicamos con familiares de las personas mencionadas en la exhibición para pedir autorizaciones y consultar puntos específicos de la sala ${ }^{31}$.

La familia de Pedro Santana prestó su DNI para incluirlo en su biografía y la de Avelino Bazán acercó fotografías personales el día de la inauguración. También Delia Maisel, compañera y biógrafa de Marina Vilte, compartió su archivo. Para nosotros, no se trata solo de documentos históricos sino de elementos cargados de afecto y significado que decidieron compartir.

Tras su participación en el armado de la exhibición y como orador en su inauguración, Nilo Cayuqueo organizó, junto a otros delegados en la ONU en 1977 y 1981, el panel "La historia de la participación de los Pueblos Indígenas en las Naciones Unidas" en el Museo. Esta presentación se enmarcó en el Taller "Archivo, Memoria y Trasmisión Oral", coordinado por el Centro de Documentación para

\footnotetext{
${ }^{30}$ Diana Lenton, Marcelo Musante, M.SolOttini y Luciana Mignoli -Red de Investigadores sobre Genocidio y Política Indígena en Argentina; Nilo Cayuqueo - Comunidad mapuche La Azotea en Los Toldos, Mesa de Pueblos Originarios de la Provincia de Buenos Aires; Santiago Garaño - Equipo de Antropología Política y Jurídica (FFyL-UBA); Delia Maisel, autora de los libros "Rebeliones mineras" y "Memorias del Apagón"; Nidia Buttori, antropóloga, docente de la Universidad Nacional de las Artes y trabajadora jubilada del ME; Francisco Chaile, cacique de la Comunidad Indígena Quilmes de Tucumán; Andrés Serbín, antropólogo; M. Victoria Pierini, de la Sección Etnohistoria (ICA-FFyL); Carlos Bartolomé, fotógrafo y documentalista; Sofía D'Andrea, autora del libro "Marina Vilte: blanco en los 70".

${ }^{31}$ Algunos de ellos se hicieron presentes el día de la inauguración y otros fueron contactados poco después cuando pudimos conseguir sus contactos. En este último caso, nos comunicamos para informarles acerca de la existencia de la muestra y cómo se vincula con ellos.
}

los Pueblos Indígenas (DOCIP) que buscaba vincular diferentes generaciones de referentes indígenas de la región. Cayuqueo también propuso exponer los paneles de la primera versión de la exhibición en el II Congreso Internacional de Pueblos Indígenas de América Latina, en la sede de la Universidad Nacional de La Pampa. Estas propuestas y aportes marcan, a nuestro entender, una validación de su parte y la importancia de incorporar estos relatos al Museo.

En cuanto a las repercusiones institucionales, destacamos los vínculos con sitios de memoria y museos que trabajan estos temas. La muestra pequeña itineró en el Ex ESIM - Faro de la Memoria de Mar del Plata (enero 2019) y en el Museo Imaginario-UNGS (marzo 2018). Se generaron encuentros de intercambio con sus equipos educativos y nos invitaron a exponer la experiencia en la inauguración de la muestra "40 años de Luchas y Resistencia *BRIGADA*32" en el ex CCDTyE "Club Atlético".

Al interior del equipo, se propuso hacer un recorrido de la exhibición entre los trabajadores del Museo. En ese encuentro, conversamos sobre qué ocurría en el Museo y nuestras experiencias personales durante la dictadura.

Por último, dos elementos permiten incorporar las voces de quienes recorren la exhibición. Una carpeta impresa con todas las fotografías de la sala espera ser completada por el público. Allí, una docente, por ejemplo, relató su historia familiar vinculada al barrio neuquino donde fueron secuestrados los hermanos Pichulman. El segundo es un panel con intervenciones del público a través de post it. En muchos mensajes se visibilizan las problemáticas de los derechos humanos hoy: intentos de golpe de estado, asesinatos de referentes políticos, reivindicaciones territoriales, ambientales y feministas,e incluso cuestionamientos a los museos de antropología, se visibilizan y se convierten en "textos de sala".

\footnotetext{
32 La muestra de afiches fue una iniciativa de Londres 38 (Chile), espacio de memorias y el colectivo Serigrafía instantánea.
} 


\section{Consideraciones finales}

A lo largo de este trabajo hemos intentado mostrar cómo las discusiones en torno a lo patrimonial, el rol político-social de los museos antropológicos y las formas de definir y exhibir las colecciones se articulan con un proyecto institucional iniciado hace más de dos décadas en el ME y con el desarrollo de la exhibición Desafiando al silencio. En la década del 80 la Revista Runa dio cuenta de esas primeras reflexiones y transformaciones al interior del Museo y nuevamente es el espacio para reflejar sus implicancias y desafíos actuales.

En los albores del siglo XXI, la institución museo y sus colecciones continúan siendo parte de un debate sobre la cultura material, el patrimonio, la identidad, la representación de la diversidad cultural y las prácticas museológicas, más aún hoy cuando lo patrimonial se complejiza, se amplía y democratiza a partir de grupos que elaboran su diferencia discursiva y simbólicamente en torno a distintas categorías -étnicas, género, etc.- y dentro de una política de identidad.

En particular para los museos antropológicos, el creciente protagonismo político de las comunidades indígenas, poniendo en discusión su papel como guardianes del patrimonio y del rol del Estado, llevó a las instituciones a replantearse la distancia que separa a sus colecciones y sus actividades de las comunidades a las que han pretendido representar e involucrar $y$, sobre todo, a cuestionar su interpretación de la historia y el control del pasado (Podgorny y Miotti, 1998; Endere, 2000; Tamagno, 2009).

Desde esta forma de entender el patrimonio y el nuevo papel de los museos en la sociedad contemporánea y la relación con los pueblos indígenas, la exhibición "Desafiando al silencio" nos lleva a pensar nuestra práctica de producción museológica en palabras de lo que Smith (2011) define también como parte del proceso de patrimonialización: no percibir al "patrimonio" como una "cosa", un lugar o un evento intangible, y pensarlo como una representación o un proceso cultural interesado en negociar, crear y recrear recuerdos, valores y significados culturales (Smith, 2011).

Esta exposición es relevante en tanto y en cuanto no sólo integra el activismo indígena en su participación social, política, partidaria, sindical, estatal, etc. sino que también recupera la reflexión sobre el genocidio, la historia y la memoria reciente. Así, la exhibición se posiciona en defensa de los procesos de Memoria, Verdad y Justicia, y es un compromiso con los 30.000 detenido/ as desaparecido/as y con otras reivindicaciones de los pueblos originarios en la lucha por sus derechos.

Todo museo es un espacio político. La decisión de hablar del genocidio fundante del Estado nacional en el siglo XIX, y del genocidio reorganizador del siglo XX, también es política. Hablar de Celestino Aigo, Abelardo Coifin, Juan Raúl Pichulmán y José Francisco Pichulman, Pedro Santana, Avelino Bazán, Marina Vilte, Jesús Costilla, Eulogio Frites y Nilo Cayuqueo, dar cuenta de sus vidas, de sus luchas, sus proyectos, sus dolores y sus alegrías es contribuir a su reconocimiento como sujetos históricos, como sujetos de derecho, como eran, como son, y habilitar senderos para proyectar cómo queremos vivir hoy.

"La memoria no señala la ruptura sino la continuidad.
No recuerda a los ausentes que no volverán
sino que vuelve una mirada preocupada
por aquellos que están y no pueden volver a faltar"33

\section{Agradecimientos}

Financiamiento: Proyecto FILO:CyT "La representación de la diversidad cultural en las exhibiciones del Museo Etnográfico "Juan B. Ambrosetti", FFyL-UBA, 1987-2018". FC19-035. Directora: Dra. Andrea Pegoraro. Asimismo, las/los autoras/es son parte del equipo directivo y docente de la Especialización en Museos Transmisión cultural y Manejo de colecciones antropológicas e históricas. FFyL-UBA.

\section{Bibliografía}

Arantes, A. (1984). Produzindo o pasado. Estrategias de construçao do patrimonio cultural. São Paulo: Brasiliense, Secretaria de Estado da Cultura, Governo Democrático de São Paulo, CONDEPHAAT.

Arantes, A. (1989). La preservación del patrimonio como práctica social. Ceballos, R. (comp). Antropología y políticas culturales. Patrimonio e identidad. Buenos Aires: Departamento Nacional de Antropología y Folklore.

Arenas, P. (1990). Las cartas: documentos para una historia de la Antropología Argentina. Runa, archivos para las ciencias del hombre, vol. 19. Año 1988-1989. 223-229.

Basualdo, V. [et al.] (2016). Responsabilidad empresarial en delitos de lesa humanidad. Represión a trabajadores durante el terrorismo de Estado. Tomo I. Buenos Aires: Editorial Ministerio de Justicia y Derechos Humanos de la Nación.

Bastías, M. (2013). Los derechos culturales en los museos de América latina. Institucionalidad, mapeo y buenas prácticas, abril - julio 2013. InterArts. doi: http://www. interarts.net/descargas/interarts1720.pdf

Becerra, M. F., Crespo, C. F., Pierini, M. V., Ramírez, V., Rodríguez, L. B., Sidy, B. L. \& Tolosa, S. (2013). Dinámicas

\footnotetext{
33 Editorial de la Revista Puentes, Comisión Provincial de la Memoria, Nov. 2015, pp.2-3
} 
de poder y saber en la reconstrucción de la Ciudad Sagrada de Quilmes (Tucumán 1977-1981). Alteridades, 23(46), 67-77.

Bennet, T. (1995). The birth of the museum. Theory and Politics. London/New York: Routledge.

Bonfil Batalla. G. (1989). Identidad nacional y patrimonio cultural: los conflictos ocultos y las convergencias. Ceballos, R. (comp). Antropología y políticas culturales. Patrimonio e identidad. Buenos Aires: Departamento Nacional de Antropología y Folklore.

Bonfil Batalla. G. (1993). Nuestro patrimonio cultural: un laberinto de significados. Florescano, E. (comp) El patrimonio cultural en México. México: Fondo de Cultura Económica.

Bustamante, J. (2012). Museos de antropología en Europa y América Latina: crisis y renovación. A modo de presentación. Revista de Indias, vol 72 (254), 1114. doi: http://revistadeindias.revistas.csic.es/index. php/revistadeindias/issue/view/93

Calveiro, P. (1998). Poder y desaparición. Los campos de concentración en Argentina. Buenos Aires: Editorial Colihue.

Camarena Ocampo, M., Morales Lersch, T. \& Necoechea Gracia, G. (1994). Reconstruyendo Nuestro Pasado. Técnicas de Historia Oral. México: I.N.A.e H. Consejo Nacional para la Cultura y las Artes; Dirección General de Culturas Populares, Programa de Museos Comunitarios y Ecomuseos.

Carta Cultural Iberoamericana. XVI Cumbre Iberoamericana de Jefes de Estado y de Gobierno Montevideo, Uruguay 4 y 5 de noviembre de 2006. doi: https://www.oei.es/xvi/xvi_culturaccl.pdf

Chagas, M. \& Gouveia, I. (2014). Museologia social: reflexões e práticas (à guisa de apresentação. Cadernos do CEOM, 27 (41).

Clifford, J. (1988). The predicament of culture. Twentieth-Century Ethnography, Literature, and Art. Harvard: Harvard UniversityPress.

De Varine-Bohan, H. (1979). Los museos en el mundo. Barcelona: Editorial Salvat.

Declaración de la Ciudad de Salvador (2007). Primer Encuentro Iberoamericano de Museos. Brasil. doi: http://www.ibermuseos.org/wp-content/ uploads/2018/10/declaracion-de-salvador-pt-esp. pdf
Dias, N. (2006). What's in a name? Anthropology, Museums and Values, 1827-2006, Cordula Grewe (Hrsg). Die Schau des fremden Ausstellungskonzepte Zwischen, kunst, kommerz und wissenschafi. Stuttgart: Franz Steiner Verlag, 169-187.

Dubuc, E. (2002). Entre l'art et l'autre, l'émergence du sujet. Gonseth, M-O., Hainard, J. \& Kaehr, R. (ed.). Le musée cannibale. Neuchâtel: Musée d'étnographie.

Dujovne, M; Pegoraro, A \& Pérez Gollán, J. A. (1997). Los trabajos de Ambrosetti o la formación de un acervo institucional a principios de siglo, Actas del Simposio Patrocinio y Circulación de las Artes. México: UNAM, 533-551.

Endere, M, L. (2000). Arqueología y legislación en Argentina. Cómo proteger el patrimonio arqueológico. Olavarría: INCUAPA.

Feierstein, D. (2007). El genocidio como práctica social. Entre el nazismo y la experiencia argentina. Buenos Aires: Fondo de Cultura Económica.

Florescano, E. (comp) (1993). El patrimonio Cultural en México. México: Fondo de Cultura Económica. García Canclini, N. (1989). Culturas híbridas. Estrategias para entrar y salir de la modernidad. México: Grijalbo.

García Canclini, N. (2010). Las sociedades sin relato. Antropología y estética de la inminencia. Buenos Aires: Katz Conocimiento.

Geertz Fabien, V., Arrieta Urtizberez, I. \& Roige, X. (2016). Los museos de antropología. Del colonialismo al multiculturalismo. Debates y estrategias de adaptación ante nuevos retos políticos, científicos y sociales. OPSIS, CatalãoGO, 16 (2) 342-360. doi: https://www. researchgate.net/publication/318667237_Los_ museos_de_antropologia_del_colonialismo_al_ multiculturalismo_Debates_y_estrategias_de_ adaptacion_ante_los_nuevos_retos_politicos_ cientificos_y_sociales

Hainard, J. (2007). La expologia a su justa medida. La museografía en el Museo de Etnografía de Neuchâtel. Quaderns-e de l'InstitutCatalád'Antropología. Núm.:09/a. Elsmuseusd'etnologia a debat. Hein, H. (2000). The museum in transition. Washington and London: Smithsonian Intitution Press.

Hobsbawm, E. (2013). Patrimonio. Un tiempo de rupturas. Sociedad y Cultura en el siglo $X X$. Barcelona: Crítica, 143-153. 
Imbelloni, J. (1948). Cuatro Palabras. Runa, archivos para las ciencias del hombre, 1, Año: 1948. 5-7. Buenos Aires.

Jeria, V. (2016). Patagonia 1973: Historias del Museo Etnográfico en la Universidad Nacional y Popular de Buenos Aires. Fragmentos del pasado - do Passado, 2, 9-28 ISSN 2525-1775 doi: https://www. fundacionazara.org.ar/img/revista-fragmentos-delpasado/002/fragmentos-2016-002-09-28.pdf

Jeria, V. \& Stáffora, V. (2016). Proyecto de exhibición Desafiando al silencio: pueblos indígenas y dictadura. Mimeo.

Kavanagh, G. (1994). Museums and the first war world. A social history, London and New York: Leicester University.

Kirshenblatt-Gimblett, B. (1998). Destination Culture. Tourism, Museums, and Heritage. Berkeley: University of California Press,.

Lenton, D. (2014) Memorias y silencios en torno a la trayectoria de dirigentes indígenas en tiempos represivos. Universidad Nacional de Río Cuarto. Facultad de Humanidades; Tefros; 12 (2); 190-211.

Lenton, D. (2015). Notas para una recuperación de la memoria de las organizaciones de militancia indígena. Identidades, 8. Universidad Nacional de la Patagonia San Juan Bosco. Instituto de Estudios Sociales y Políticos de la Patagonia. 117-154.

Lorandi, A. \& Peréz Gollan, J. A. (1990). Nota Editorial. Runa, Archivo para las Ciencias del Hombre, 19, 1989-1990. 7-9.

Pegoraro, A. (2005). Instrucciones y colecciones en viaje. Redes de recolección entre el Museo Etnográfico y los Territorios Nacionales. Anuario de Estudios en Antropología Social, Centro de Antropología Social, IDAES, 49- 64.

Pegoraro, A. (2009). Las Colecciones del Museo Etnográfico de la Universidad de Buenos Aires: un episodio en la historia del Americanismo en la Argentina 1890-1927, Tesis de Doctorado, FFy L (UBA). doi: http://repositorio.filo.uba.ar/handle/ filodigital/1388

Pegoraro, A. (2018). Nuevos contextos, temas y problemas de un museo universitario y antropológico de la Universidad de Buenos Aires. México: Gaceta de museos 71. 48-58.

Perez Gollan, J.A. (1992) Agrupar esfuerzos. Buenos Aires: Runa, Archivo para las Ciencias del Hombre, 20 (1), 9-10.
Pérez Gollán, J. A. \& Dujovne, M. (1995). El Museo Etnográfico de la Facultad de Filosofía y Letras: balance de una gestión. Buenos Aires: Runa, Archivo para las Ciencias del Hombre, 22, 119-131.

Podgorny, I. \& Politis, G. G. (1992). ¿Qué sucedió en la historia? Los esqueletos araucanos del Museo de La Plata. Arqueología contemporánea, 3. $73-90$

Miotti, L. \& I. Podgorny, (1998) Una flecha en mi sopa. La convivencia con los restos arqueológicos en la región del Río Deseado, Pcia. de Santa Cruz, Rca. Argentina: Cuadernos del Instituto Nacional de Antropología y Pensamiento Latinoamericano, 16, 343-35.

Resoluciones de la Mesa Redonda sobre la importancia y el desarrollo de los museos en el mundo contemporáneo, Santiago de Chile, 1972. doi: http://www.ibermuseus.org/wp-content/ uploads/2014/07/copy_of_declaracao-da-mesaredonda-de-santiago-do-chile-1972.pdf

Simpson, M. (2009). Museums and restorative justice. Heritage, repatriation, and cultural education: Museum International, Unesco, 61, (Issue 1-2), 121129.

Smith, L. (2011). El espejo patrimonial ¿llusión narcisista o reflexiones múltiples. Antípoda. Rev. Antropol. Arqueol. 12. Bogotá: Uniandes, 39-63.

Smith, L. (2011). All heritage is intangible: Critical heritage studies and museums. Amsterdam: Reinwardt Academie, Amsterdamse Hogeschoolvoor de Kunsten.

Sosa, J. (2007). 'Ruinas' de Quilmes. Historia de un despropósito. doi: http://media.argentina. indymedia.org/uploads/2008/01/kilmes.pdf.

Stocking, G .W. (Jr) (1985) Objetcs and Others. Essay in museum and material Culture, History of Anthropology, 3. Madison: University of Wisconsin Press.

Tamagno, L. (2009). Pueblos indígenas. Interculturalidad, colonialidad, política, Buenos Aires: Biblos.

Tarragó, M. N. \& Calvo, S. L. (2019). La representación del pasado en un museo de antropología. Experiencias en la República Argentina. Revista del Museo de La Plata 4 (1), 209-250. doi: https://doi. org/10.24215/25456377e075 
Tomás, A.A. (2012). Los museos de etnología; entre la redefinición y la transformación. ILHA Revista de Antropología, Vol 4, n' 1, 83-114. doi: http://dx.doi. org/10.5007/2175-8034.2012v14n1-2p83

Van Geertz, F \& Roigé X. (2016). De los usos políticos del patrimonio. Van Geertz, F y Roigé $X$ y Conget,
L, (editores) Usos políticos del patrimonio cultural. Barcelona: Universitat de Barcelona.

Volkert, J. (1997). Los museos en los albores del siglo XXI. Ciencia Hoy, 7 (39). 10-15 doi: https:// cienciahoy.org.ar/los-museos-en-los-albores-delsiglo-xxi/ 